\title{
Management of paediatric traumatic cataract by epilenticular intraocular lens implantation: long- term visual results and postoperative complications
}

\begin{abstract}
Purpose This study was carried out to evaluate the postoperative visual results and complications following epilenticular intraocular lens implantation in paediatric traumatic cataracts.

Materials and methods A total of 30 patients undergoing epilenticular intraocular lens implantation for traumatic pediatric cataract were evaluated prospectively for visual results and complications. After-cataract formation was the prime area of interest. Follow-up of patients ranged from 2 to 8 years (mean 5 years). In all, $90 \%$ of eyes had a visual acuity of $6 / 60$ or worse at the time of presentation.

Results In total, $80 \%$ of our patients achieved a visual acuity of 6/12 or better postoperatively after a mean follow-up of 5 years. None of our patients had after-cataract formation and the visual axis remained clear until the last follow-up in all the patients.

Conclusion Epilenticular intraocular lens implantation in paediatric traumatic cataracts is associated with favourable anatomic and visual results.

Eye (2004) 18, 126-130. doi:10.1038/

sj.eye. 6700605
\end{abstract}

Keywords: epilenticular; paediatric traumatic cataract; intraocular lens; visual results

\section{Introduction}

Trauma remains one of the most important causes of childhood cataract in India. ${ }^{1}$ Intraocular lens (IOL) implantation has been
Kamlesh and S Dadeya

accepted as the popular method of correcting aphakia in children because of disadvantages of contact lenses and epikeratophakia., ${ }^{2,3}$ This is true especially for developing countries like India, where parents are not much educated to take care of contact lenses. Furthermore, at the age of 2 years, even in the Western world, IOL implantation remains the preferred mode of rehabilitation of aphakia. There are various aspects of IOL implantation surgery in children, especially in traumatic cataract, which are still controversial. Amidst these controversies, one thing is clear that the visual pathway must be clear after surgery to provide satisfactory visual acuity and prevent amblyopia, because management of amblyopia in this age group often yields poor results. ${ }^{4,5}$ However, with refinement of microsurgical techniques, use of viscoelastic agents and availability of newer and better IOL design, and initiation of aggressive amblyopia therapy, the results of paediatric cataract surgery are comparable to those of adults. ${ }^{6,7}$

It is currently accepted that primary posterior capsulotomy and anterior vitrectomy are necessary to maintain a clear visual axis, especially in young children. ${ }^{8}$ Posterior curvilinear continuous capsulorhexis with optic capture of IOL is currently used for paediatric cataract. However, in traumatic cataracts, it might not be feasible. This study is an attempt to overcome certain notorious complications (high positive pressure, fibrinous uveitis, and thick or densely opacified posterior capsule), in implanting IOL in paediatric patients. ${ }^{9-12}$ Ghosh et $a l^{13}$ reported encouraging results after epilenticular IOL implantation. However, to the
No public or private support for the study 
best of our knowledge, long-term results after epilenticular IOL implantation in traumatic paediatric cataract have not been reported. In this study, we prospectively evaluated visual results and complications following epilenticular IOL implantation in traumatic paediatric cataracts on a long-term basis.

\section{Materials and methods}

A total of 36 patients of traumatic cataract were included in this prospective study from 1992 to 2000. All the patients underwent complete ophthalmic examination including comprehensive history for duration of dimness of vision and nature of trauma, best-corrected visual acuity, refraction, presence of squint, nystagmus and fixation pattern, and fundus examination, wherever possible. Slit-lamp examination was carried out wherever possible. B-scan ultrasonography was carried out to find out posterior segment pathology. All children in whom traumatic cataract was associated with iridodialysis of more than $180^{\circ}$, corneal laceration more than $10 \mathrm{~mm}$, gross pupillary distortion, and posterior segment pathology, and children less than 2 years of age were excluded from the study.

IOL power was calculated using the modified SRK-II formula based on keratometry and axial length reading with the aim of attaining emmetropia or to match the refractive error in the fellow eye. Whenever corneal trauma precluded keratometry measurements, the same from the fellow eye were used. Written informed consent of parents of patients prior to surgery was taken and parents were given information regarding risks and benefits of the procedure. Surgery was performed under general anaesthesia and anaesthetists were asked to provide low intraocular tension during surgery. Single surgeon $(\mathrm{K})$ performed all the surgeries.

\section{Surgical procedure}

After cleaning and draping, lid and superior rectus sutures were applied. A fornix-based conjunctival flap was made. Two full-thickness sclerotomies were made in superonasal and superotemporal quadrant $3.0 \mathrm{~mm}$ from the limbus. The anterior chamber was entered with a stab incision. Healon was injected and the section was enlarged. Posterior chamber IOL (CeeOn heparin surface-modified 811C) was put over the anterior capsule and the limbal section was closed. Pars plana lensectomy was carried out, first lenticular matter was removed intercapsularly and then an opening was made in the centres of the anterior and posterior capsules. Only the peripheral parts of the anterior and posterior capsules, along with cortical matter, were left. Anterior vitrectomy was also performed. Sclerotomies were closed with 8-0 monofilament sutures. Subconjunctival injection of gentamycin and dexamethasone was given. At the end of surgery, pad and bandage applied. Postoperatively, all patients received intensive topical steroids every $2 \mathrm{~h}$ for 1 week and four times a day for 4 weeks along with antibiotics (ciprofloxacin $0.3 \%$ ) for 1 week.

All patients received cyclomid 1\% thrice a day for 2 weeks. Oral prednisolone $1 \mathrm{mg} / \mathrm{kg}$ body weight was given to all patients for 2 weeks. Occlusion therapy according to thumb-age rule was instituted immediately after the surgery in all children below 7 years of age. All patients were followed on first, seventh, 30th postoperative days, once a month for 6 months and every 6 months till last follow-up; additional follow-ups were done if some patients had problems. However, the results of last follow-up were analysed for the purpose of the study. Postoperatively, visual acuity, refraction, and slitlamp and fundus examinations were performed on each follow-up visit. Posterior capsule opacification, fibrinous uveitis, and other complications were prime areas of interest.

\section{Results}

In total, 36 consecutive patients of traumatic cataract in paediatric age group were included from 1992 to 2000 in this study. six patients were lost to follow-up and were excluded from the study. The age of patients ranged from 2 to 12 years (mean 7 years). Among them, 22 patients were male and eight patients female. The preoperative characteristics and intraoperative complications are summarized in Table 1. Concussional trauma was more common than penetrating trauma as the cause of cataract. Cricket ball injury and bow and arrow injury were the common causes of injury. The average interval between injury and surgery was 2.6 months.

Posterior capsular tear (about $3 \mathrm{~mm}$ in size) was seen in six patients $(20 \%)$, loose lens matter was present in three patients $(10 \%)$, and adherent leucoma in two patients $(6.66 \%)$. Vitreous upthrust (increased vitreous pressure) was noted in almost all the patients. Posterior synechiae were present in three patients $(10 \%)$ and subluxated lens in three patients $(10 \%)$. These have been tabulated in Table 2.

The postoperative complications are shown in Table 3. These included transient corneal striae in five patients $(16.66 \%)$, pupillary capture in one patient $(3.33 \%)$, IOL decentration in one patient $(3.33 \%)$, and a persistent postoperatively raised intraocular pressure in one patient (3.33\%). Postoperatively, up-drawn pupil and corneal oedema were seen in one patient each (3.33\%). The most important finding noted by us was that none of the patients had posterior capsular opacification (anterior vitreous opacification) after a mean follow-up of 5 years. 
Table 1 Preoperative characteristics of the patients

\begin{tabular}{lc}
\hline Characteristic & \\
\hline No. of patients & 30 \\
Male & 22 \\
Female & 08 \\
Age of patients (years) & \\
Range & $2-12$ \\
Mean & 7 \\
Mode of injury & No. of patients \\
Bow and arrow & 9 \\
Wooden stick & 4 \\
Cricket ball & 5 \\
Fire cracker & 4 \\
Broomstick & 3 \\
Stone & 2 \\
Others & 3 \\
Interval between injury and surgery (mean) & 2.6 months \\
Range & $2-5$ months \\
Associated finding & No. of patients \\
Corneal scar & 2 \\
Iris hole & 1 \\
Synechiae & 3 \\
Capsule rupture & 4 \\
Lens matter in anterior Chamber & 3 \\
\hline
\end{tabular}

Table 2 Intraoperative findings in the study group

\begin{tabular}{lcc}
\hline Complication & No. of eyes & Percentage \\
\hline Posterior capsule & 6 & \\
tear & 3 & 20 \\
Loose lens matter & 3 & 10 \\
Posterior synechiae & 30 & 10 \\
Vitreous upthrust & 3 & 100 \\
Subluxated lens & & 10 \\
\hline
\end{tabular}

Table 3 Postoperative complications

\begin{tabular}{lcc}
\hline Characteristic & No. of eyes & Percentage \\
\hline Transient corneal striae & 5 & 16.66 \\
Pupillary capture & 1 & 3.33 \\
IOL decentration & 1 & 3.33 \\
Raised intraocular pressure & 1 & 3.33 \\
Corneal oedema & 1 & 3.33 \\
Up-drawn pupil & 1 & 3.33 \\
Postoperative ptosis & 1 & 3.33 \\
Postcapsule opacification & - & - \\
Fibrinous uveitis & - & - \\
\hline
\end{tabular}

The follow-up of patients in our series ranged from 2 to 8 years. The mean follow-up was 5 years.

In total, $80 \%$ of our patients achieved a visual acuity of $6 / 12$ or better. Table 4 shows the postoperative visual acuity. The cause of poor visual acuity included corneal scaring in three patients (10\%), corneal oedema in one $(3.33 \%)$, persistent raised intraocular pressure in one patient $(3.33 \%)$, IOL decentration in one patient $(3.33 \%)$,
Table 4 Postoperative visual acuity at the last follow-up

\begin{tabular}{lcc}
\hline Visual acuity & No. of patients & Percentage \\
\hline $6 / 6$ & 6 & 20 \\
$6 / 9$ & 9 & 30 \\
$6 / 12$ & 9 & 30 \\
$6 / 18$ & 1 & 3.33 \\
$6 / 24$ & 1 & 3.33 \\
$6 / 36$ & 1 & 3.33 \\
$6 / 60$ or less & 3 & 10 \\
\hline
\end{tabular}

Table 5 Causes of poor visual acuity

\begin{tabular}{lcc}
\hline Characteristic & No. of patients & Percentage \\
\hline Corneal scar & 3 & 10 \\
Macular scar & 1 & 3.33 \\
Nystagmus & 1 & 3.33 \\
Corneal oedema & 1 & 3.33 \\
Amblyopia & 1 & 3.33 \\
IOL decentration & 1 & 3.33 \\
Raised intraocular pressure & 1 & 3.33 \\
\hline
\end{tabular}

and amblyopia in one patient (3.33\%). These have been tabulated in Table 5.

\section{Discussion}

Extracapsular cataract extraction with IOL implantation is the safe and preferred method of rehabilitation of traumatic cataract in children. Various authors ${ }^{1,9,11,14-16}$ have reported excellent visual results (Table 6). On the other hand, numerous complications have been reported on follow-up and authors were not able to achieve visual results comparable to adults in cases of childhood cataract because of complications peculiar to that age group. ${ }^{17-21}$ High positive pressure during surgery, fibrinous uveitis, and thick after-cataract resistant to YAG-laser are the most commonly encountered complications, which are obstacles in maintaining a clear visual pathway, and thereby increase the risk of eyes becoming amblyopic or strabismic. ${ }^{9,11,13,15,17,22-24}$ In all, $80 \%$ cases in a lens aspiration group in a study by Ghosh et $a l^{13}$ had posterior capsule opacification. Moreover, high positive vitreous pressure makes anterior chamber manoeuvring difficult. However, we are of the opinion that posterior capsular opacification, fibrinoid reaction, and high positive pressure are frequently seen complications with extracapsular cataract extraction in paediatric cataracts and we have abandoned the procedure in favour of epilenticular IOL.

The most serious and vision-impairing complication of paediatric cataract surgery is posterior capsular opacification. The incidence of posterior capsular opacification varies from 21 to $100 \% .{ }^{14-24}$ Although 
Table 6 Visual results reported by various authors

\begin{tabular}{lccc}
\hline Authors & Visual acuity & Percentage & $\begin{array}{c}\text { Follow-up } \\
\text { (months) }\end{array}$ \\
\hline Gupta et l $^{16}$ & $6 / 12$ & 50 & 09.00 \\
Bustos al $^{32}$ & $6 / 12$ & 79 & 21.00 \\
Ben Ezra et $^{26} l^{26}$ & $6 / 12$ & 65.2 & 88.00 \\
Eckstein et $^{1} l^{1}$ & $6 / 12$ & 67 & 33.00 \\
Pandey al $^{9}$ & $6 / 12$ & 80 & 24.60 \\
Current study & $6 / 12$ & 80 & 60.00 \\
\hline
\end{tabular}

various options to prevent posterior capsule opacification have been suggested, none is foolproof. Attempts have been made and several techniques are described to prevent posterior capsular opacification like lensectomy and vitrectomy, ${ }^{6}$ posterior capsulotomy at the time of surgery, ${ }^{25}$ limbal approach retropseudophakic vitrectomy, ${ }^{26}$ scleral tunnel in the bag IOL insertion with pars plana capsulectomy and vitrectomy. ${ }^{27}$ However, these are associated with complications like retinal detachment, ${ }^{14}$ IOL dislocation, and rarely cystoid macular oedema. ${ }^{28}$ Moreover, some surgeons are reluctant to disturb the vitreous phase during lens implantation.

Fibrinous uveitis is a common postoperative complication after cataract surgery in children. ${ }^{15-17}$ It is caused by a fibrinous uveal reaction to fine proteinaceous lens particles interacting with aqueous humour or contact of the IOL with highly vascularised adjacent uveal tissue. Since in epilenticular IOL implantation, manipulation through anterior chamber is less, there is minimal reaction. Moreover, the use of heparin surface-modified IOL in all patients and frequent topical and systemic steroids in all patients might have contributed to the absence of severe fibrinous reaction in our study.

Most of the surgeons believe that primary management of the posterior capsule and anterior vitreous is important during cataract removal in young children. Many surgeons for treatment of congenital cataract use posterior capsulorhexis with optic capture of IOL. ${ }^{8}$ However, this technique is demanding. Another disadvantage of this procedure is greater difficulty in IOL exchange if required at a later stage. Furthermore, it might not be feasible in unilateral traumatic cataracts in which posterior capsular status is either unknown or has large rent. Safety and efficacy of anterior chamber and scleral fixated IOLs in paediatric patients have not been studied. Moreover, Koch and Kohnen ${ }^{29}$ report that four of five eyes with optic capture without anterior vitrectomy developed visually significant postcapsular opacification by 2.5 years post operatively. Furthermore, paediatric ophthalmologists recommend lensectomy without IOL implantation, a large posterior capsulotomy, and an anterior vitrectomy to minimise the risks of secondary cataract.

Epilenticular IOL implantation is simple to perform, provides a stable and well-centred IOL and maintains a clear visual pathway. Since in this technique, IOL is placed over the cataractous lens, its insertion and centration is ensured and all the problems of paediatric cataract are effectively tackled by this procedure. Moreover, the surgical procedure is minimally affected by positive vitreous pressure. Vitreous upthrust was a major intraoperative problem in cataract surgery. With the advent of small incision and use of high-viscosity viscoelastics, it is not so common. There have been reports of opacification of posterior capsule after primary capsulectomy and vitrectomy. Therefore, a large posterior capsular opening without affecting the stability of IOL should be ideal. Ghosh et $a l^{13}$ obtained $100 \%$ clear visual pathway in all patients with epilenticular IOL implantation. Similarly, Tablante et $a l^{30}$ also obtained $100 \%$ clear visual pathway in 47 eyes. Posterior capsule opacification, fibrinous uveitis, and positive pressure were effectively tackled by our technique. We also achieved $100 \%$ clear visual pathway after a mean followup of 5 years. Although ciliary sulcus-fixated IOL may not be as ideal as a capsule-supported IOL in paediatric age group, it can still be considered an acceptable alternative in this situation. The possible causes of concern with our technique include constant uveal contact with epilenticular placement of IOL and the possibility of retinal detachment in the long term due to inadvertent vitreous traction. Furthermore, there is a possibility of dropping of lens matter into vitreous and occurrence of fibrinous uveitis, if whole cortex is not removed. However, we did not encounter any of the above-mentioned complications after a mean follow-up of 5 years. However, these are still valid concerns and will be only addressed with continued follow-up of these eyes.

Attainment of good vision was a difficult task two decades ago. Successful visual rehabilitation has now dramatically changed the situation. It has been proved beyond doubt that early cataract extraction and intensive occlusion therapy initiated during the initial period of development of visual perception now achieve high success rates. We are of the opinion that 3-6 weeks duration of total occlusion from the second postoperative day in patients of less than 7 years of age, followed by partial occlusion and proper compliance with a little extra effort by the parents, is a must for better results.

We obtained 6/12 or better visual acuity after epilenticular IOL implantation after a mean follow-up of 5 years in $80 \%$ of our patients. In the current study, after a mean follow-up of 60 months, we did not encounter posterior capsular opacification and fibrinous reaction in 
any of the patients. We, therefore, recommend that epilenticular IOL implantation in traumatic paediatric cataract is a safe and effective procedure to tackle most of the problems associated with traumatic paediatric cataract.

\section{References}

1 Eckstein M, Vijayalakshmi P, Killedar M. Etiology of childhood cataract in south India. Br J Ophthalmol 1996; 80: 628-632.

2 Dahan E, Salmeson BD. Pseudophakia in children: precautions, techniques and feasibility. J Cataract Refract Surg 1990; 16: 75-82.

3 Kelley CG, Keates RH, Lembach RG. Epikeratophakia for pediatric aphakia. Arch Ophthalmol 1986; 104: 680-682.

4 Dutton JJ, Baker JD, Hiles DA, Morgan KS. Visual rehabilitation of aphakic children. Surv Ophthalmol 1990; 34: 365-384.

5 Taylor D. Monocular infantile cataract. Intraocular lenses and amblyopia. Br J Ophthalmol 1989; 73: 857-858.

6 Cheng KP. Treatment of pediatric cataracts. Ophthalmic Clin N Am 1996; 9(2): 239-247.

7 Wilson ME, Bluestein EC, Wang XH. Current trends in the use of intraocular lenses in children. J Cataract Refract Surg 1994; 20: 597-583.

8 Gimbel HV. Posterior capsulorhexis with optic capture in pediatric cataract and intraocular lens surgery. Ophthalmology 1996; 103: 1871-1875.

9 Pandey SK, Ram J, Werner L, Brar GS. Visual results and postoperative complication of capsular bag and cilliary sulcus fixation of posterior chamber intraocular lens in children with traumatic cataracts. I Cataract Refract Surg 1999; 25: 1577-1584.

10 Eckstein M, Vijayalakshmi P, Killedar M, Gilbert C, Foster A. Use of intraocular lenses in children with traumatic cataract in south India. Br J Ophthalmol 1998; 82: 911-915.

11 Sharma N, Pushker N, Dada T, Vajpayee RB, Dada VK. Complications of pediatric cataract surgery and intraocular lens implantation. J Cataract Refract Surg 1999; 25: 1585-1588.

12 Zwaan J, Mullaney PB, Awad A. Pediatric intraocular lens implantation. Surgical results and complications in more than 300 patients. Ophthalmology 1998; 105: 112-119.

13 Ghosh B, Gupta AK, Taneja S, Gupta A, Mazumder S. Epilenticular versus extracapsular cataract extraction and lens implantation in children. J Cataract Refract Surg 1997; 23: 612-617.

14 Koenig SB, Ruttum MS, Lewandowski MF, Schultz RO. Pseudophakia for traumatic cataracts in children. Ophthalmology 1993; 100: 1218-1224.
15 Brar GS, Ram J, Pandav SS, Reddy GS, Singh U, Gupta A. Postoperative complications and visual results in uniocular pediatric traumatic cataract. Ophthalmic Surg Lasers 2001; 32: 233-238.

16 Gupta AK, Grover AK, Gurha N. Traumatic cataract surgery with intraocular lens implantation in children. J Pediatr Ophthalmol Strabismus 1992; 29: 73-78.

17 Apple DJ, Solomon KD, Tetz MR. Posterior capsule opacification. Surv Ophthalmol 1992; 37: 73-116.

18 Taylor D. Congenital cataract: the history, the nature and practice. Eye 1998; 12: 9-36.

19 Hemo I, Ben Ezra D. Traumatic cataracts in young children. Ophthalmic Paediatr Genet 1987; 8: 203-207.

20 Hiles DA, Cheng KP, Biglan AW. Aphakic optical correction with intraocular lenses for children with traumatic cataracts. Eur J Implant Refract Surg 1990; 2: 275-283.

21 Menezo JL, Esteve JT, Perez-Tonegrosa VT. IOL implantation in children: 17 years experience. Eur J Implant Refract Surg 1994; 6: 251-256.

22 Gimbel HV. Posterior continuous curvilinear capsulorhexis and optic capture of the intraocular lens to prevent secondary opacification in pediatric cataract surgery. J Cataract Refract Surg 1997; 23: 652-656.

23 Lambert SR, Drack AV. Infantile cataracts. Surv Ophthalmol 1996; 40: 427-428.

24 Mevezo JL, Taboda JF, Ferrer E. Complications of intraocular lenses in children. Trans Ophthalmol Soc UK 1985; 104: 546-552.

25 Ben Ezra D, Cohen E, Rose L. Traumatic cataract in children, Correction of aphakia by contact lens or intraocular lens. Am J Ophthalmol 1997; 123: 773-782.

26 Mackool RJ, Chhatiawala H. Pediatric cataract surgery and intraocular lens implantation: a new technique for preventing or excising postoperative secondary membranes. J Cataract Refract Surg 1991; 17: 62-66.

27 Buckley EG, Klombers LA, Seaber JH. Management of posterior capsule during pediatric intraocular lens implantation. Am J Ophthalmol 1993; 115: 722-728.

28 Rao SK, Ravishankar K, Sitalakshmi G, Ng JS, Yu C et al. Cystoid macular edema after pediatric intraocular lens implantation: fluorescein angioscopy results and literature review. J Cataract Refract Surg 2001; 27: 432-436.

29 Koch DD, Kohnen T. Retrospective comparison of techniques to prevent secondary cataract formation after posterior chamber intraocular lens implantation in infants and children. J Cataract Refract Surg 1997. 23: 657-663.

30 Tablante RT, Cruz EDG, Lapus JV, Santos AM. A new technique of congenital cataract surgery with primary posterior chamber intraocular lens implantation. J Cataract Refract Surg 1988; 14: 149-157.

31 Bustos FR, Zepeda LC, Cota DM. Intraocular lens implantation in children with traumatic cataract. Ann Ophthalmol 1996; 28: 153-157. 